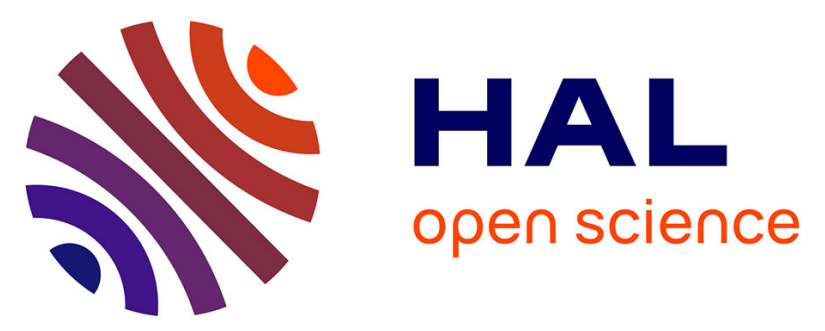

\title{
Formation and mechanical characterisation of SU8 composite films reinforced with horizontally aligned and high volume fraction CNTs
}

Liudi Jiang, S. M. Spearing, M.A. Monclus, N.M. Jennett

\section{- To cite this version:}

Liudi Jiang, S. M. Spearing, M.A. Monclus, N.M. Jennett. Formation and mechanical characterisation of SU8 composite films reinforced with horizontally aligned and high volume fraction CNTs. Composites Science and Technology, 2011, 71 (10), pp.1301. 10.1016/j.compscitech.2011.04.017. hal-00768849

\section{HAL Id: hal-00768849 \\ https://hal.science/hal-00768849}

Submitted on 26 Dec 2012

HAL is a multi-disciplinary open access archive for the deposit and dissemination of scientific research documents, whether they are published or not. The documents may come from teaching and research institutions in France or abroad, or from public or private research centers.
L'archive ouverte pluridisciplinaire HAL, est destinée au dépôt et à la diffusion de documents scientifiques de niveau recherche, publiés ou non, émanant des établissements d'enseignement et de recherche français ou étrangers, des laboratoires publics ou privés. 


\section{Accepted Manuscript}

Formation and mechanical characterisation of SU8 composite films reinforced with horizontally aligned and high volume fraction CNTs

Liudi Jiang, S. M. Spearing, M.A. Monclus, N.M. Jennett

PII:

S0266-3538(11)00150-3

DOI:

10.1016/j.compscitech.2011.04.017

Reference:

CSTE 4978

To appear in:

Composites Science and Technology

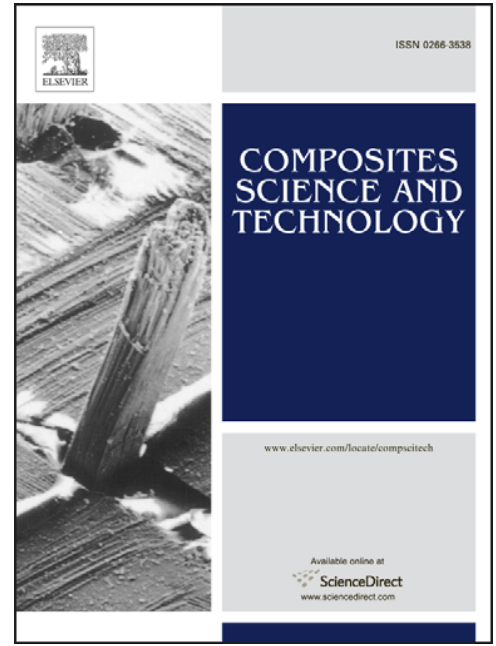

Received Date: $\quad 3$ November 2010

Revised Date: $\quad 16$ April 2011

Accepted Date: $\quad 23$ April 2011

Please cite this article as: Jiang, L., M. Spearing, S., Monclus, M.A., Jennett, N.M., Formation and mechanical characterisation of SU8 composite films reinforced with horizontally aligned and high volume fraction CNTs, Composites Science and Technology (2011), doi: 10.1016/j.compscitech.2011.04.017

This is a PDF file of an unedited manuscript that has been accepted for publication. As a service to our customers we are providing this early version of the manuscript. The manuscript will undergo copyediting, typesetting, and review of the resulting proof before it is published in its final form. Please note that during the production process errors may be discovered which could affect the content, and all legal disclaimers that apply to the journal pertain. 


\title{
Formation and mechanical characterisation of SU8 composite films reinforced
} with horizontally aligned and high volume fraction CNTs

\author{
Liudi Jiang $^{\mathrm{a},{ }^{*}}$, S. M. Spearing ${ }^{\mathrm{a}}$, M. A. Monclus ${ }^{\mathrm{b}}$ and N. M. Jennett ${ }^{\mathrm{b}}$
}

${ }^{a}$ School of Engineering Sciences, Univ. of Southampton, Southampton, SO17 1BJ, U.K.

${ }^{\mathrm{b}}$ National Physical Laboratory, Hampton Road, Teddington, U.K.

*Corresponding author.E-mail: ldjiang@ soton.ac.uk

\section{Abstract}

Carbon nanotube (CNT) reinforced composites have been identified as promising structural materials for the mechanical components of microelectromechanical systems (MEMS), potentially leading to advanced performance. High alignment and volume fraction of CNTs in the composites are the prerequisites to achieve such desirable mechanical characteristics. In particular, horizontal CNT alignment in composite films is necessary to enable high longitudinal moduli of the composites which is crucial for the performance of microactuators. A practical process has been developed to transfer CNT arrays from vertical to horizontal alignment which is followed by in-situ wetting, realign and pressurized consolidation processes, which lead to a high CNT volume fraction in the range of 46-63\%. As a result, SU8 epoxy composite films reinforced with horizontally aligned CNTs and a high volume faction of CNTs have been achieved with outstanding mechanical characteristics. The transverse modulus of the composite films has been characterised through nanoindentation and the longitudinal elastic modulus has been investigated. An experimental transverse modulus of 9.6 GPa and an inferred longitudinal modulus in the range of 460 630 GPa have been achieved, which demonstrate effective CNT reinforcement in the SU8 matrix.

Key words: "A." Carbon nanotubes; "A." Nano composites; "B." Mechanical properties. 


\section{Introduction}

Considerable research has been focused on carbon nanotubes (CNTs) reinforced polymers since initial work was conducted by Iijima [1]. CNTs have exceptional mechanical, electrical and thermal properties and their incorporation into polymer matrices can potentially lead to multifunctional composites with greatly enhanced properties [2-5]. However, to maximize the effectiveness of the reinforcement and hence the relevant properties of the composites, CNT alignment [6], dispersion [7] and volume fraction [8] have always been the major challenges in the field. Recently, a strong interest has emerged to exploit CNT reinforced composites for applications in the area of MEMS [9-11]. It was reported [9] that, CNT reinforced polymer composites can exhibit mechanical properties rivalling those of monolithic materials used in the current generation of MEMS (e.g. silicon and its compounds). Thus, they could be exploited as advanced structural materials for the mechanical components of MEMS, leading to high performance multifunctional microactuators. However, to achieve this goal, the key challenge is the formation of composite films containing highly aligned CNTs and a high volume fraction of CNTs.

Process development to achieve composites with controlled orientation of CNTs has been frequently reported [12-15]. However, these processes tend to induce detrimental structural damage to the CNTs. An in-situ polymerization process has also been developed [16] which can maintain the required CNT nano-morphology as well as their natural alignment generated by the growth process. The as-grown CNTs are vertically aligned and can be easily wetted by a polymer solution. This technique avoids the damaging step conventionally used to mix CNTs and polymers. Nonetheless, this 
method requires delamination and direct handling of free-standing blocks of CNT arrays before they can be densified by multi-axial pressure application and subsequent wetting and curing processes. This is not practical for parallel fabrication and is particularly unsuitable for the wafer level processing required by MEMS. For MEMS applications, it is also crucial to realise composite films with horizontally aligned CNTs. In contrast to vertical alignment, horizontal alignment allows a simple densification process (i.e. to achieve high volume fraction) by a uniaxial pressure. It also facilitates surface micromachining processes which include a range of key microfabrication technologies for MEMS [17]. In contrast to random alignment, the horizontal alignment can lead to a higher longitudinal modulus of the composites which is advantageous for MEMS actuators with in-plane or out-of-plane bending mechanisms [9]. The high elastic moduli are potentially advantageous for high force actuators where a high modulus and high strength material is required as well as for resonators where a high specific modulus (modulus/density) leads to a high resonant frequency. Detailed analysis of the material performance indices for typical MEMS actuator materials has been reported previously [18-20].

We report here, for the first time, a practical and effective process to develop a SU8 epoxy thin film composite reinforced by horizontally aligned CNTs with a high volume fraction. The elastic properties of the composite films have been studied and extremely high elastic moduli have been demonstrated. The developed process is also compatible with wafer-level processing. Thus, the developed SU8/CNT composite films are attractive for exploitation as superior mechanical structural materials for MEMS. 


\section{Experimental}

\subsection{Growth of aligned CNT arrays}

Silicon $(100)$ chips $\left(1 \mathrm{~cm}^{2}\right)$ covered with $1 \mu \mathrm{m}$ thick thermal oxide were used as substrates. The substrates were supplied by Siltronix with thickness of approximately $525 \mu \mathrm{m}$. Six substrates were used for each session. Photolithography was carried out to generate resist patterns, consisting of parallel lines on the substrates. Subsequently, a support layer of $\mathrm{Al}_{2} \mathrm{O}_{3}(7 \mathrm{~nm})$ followed by a thin Fe catalyst layer $(5 \mathrm{~nm})$ was sputter deposited onto the photoresist patterned substrates. A resist lift-off process was conducted to obtain catalyst lines which are $10 \mu \mathrm{m}$ wide and $100 \mu \mathrm{m}$ apart. The catalyst patterned substrates were then loaded into a horizontal quartz tube furnace for CNT growth by thermal chemical vapour deposition (CVD) at atmospheric pressure. For the growth process, the substrates were firstly annealed in a gas mixture of hydrogen (300 $\mathrm{sccm})$ and argon $(1120 \mathrm{sccm})$ at $875{ }^{\circ} \mathrm{C}$ for 30 minutes. CNT growth was then enabled at $875{ }^{\circ} \mathrm{C}$ in a gas mixture of argon $(1120 \mathrm{sccm})$ and ethylene $(300 \mathrm{sccm})$. In this work, all CNTs have been grown for 20 minutes when the ethylene gas was turned off and furnace was cooled down.

\subsection{Formation of SU8/CNT composite films}

The substrates with vertically aligned CNT arrays were immersed in, and then pulled out of the SU8 2000.5 solution as shown in Figure 1. SU8 2000.5 supplied by MicroChem Corp. consists of epoxy-based negative resists which are formulated in cyclopentanone solvent. It was chosen as the matrix material because it has low viscosity $(2.66 \mathrm{cP})$ and SU8 is also extensively used for microfabrication. The in-situ wetting process induces a capillary force between the CNTs followed by the pulling 
process, which redirects the vertically aligned CNT arrays into horizontal alignment.

This process was carried out manually and slowly with particular attention to ensure the substrate was perpendicular to the surface of the epoxy solution. Nitrogen gas was blown along the "falling" direction of the CNT arrays to improve further the flatness of the CNT "ribbons". In order to achieve a high CNT volume fraction, further densification was achieved by manually applying an arbitrary pressure to the top surface, as shown in Figure 1d. Particular attention was paid to ensure the pressure was perpendicular to the surface of the substrate. The samples were finally baked at $95{ }^{\circ} \mathrm{C}$ for 5 minutes followed by a hard bake at $200{ }^{\circ} \mathrm{C}$ for 20 minutes. As comparative studies, a blank substrate without CNTs on top underwent the same procedures depicted in Fig. 1 to obtain a control sample that contained a pure SU8 film which remained on the substrate during all the subsequent characterisation.

\subsection{Characterisation}

The micro/nanostructure of the as-grown CNT arrays and the fabricated composites were characterised using a scanning electron microscope (SEM) with a field emission gun (JEOL JSM-6500F). Using a MTS Nano Instruments Nanoindenter II with Berkovich geometry diamond indenter, nanoindentation tests were carried out according to ISO14577-4 [21] indenting in the direction perpendicular to the substrate and the composite film planes. This led to the acquisition of the transverse elastic modulus of the composite films. Three samples were tested by nanoindentation including sample A, B, and C which contain a pure SU8 film, a SU8 film reinforced with horizontally aligned CNTs without the densification step and a SU8 film reinforced with horizontally aligned CNTs with the densification step, respectively. The quasi-static 
nanoindentation tests were designed, performed and analysed using previously described methods [22]. For each sample, five indentations at $50 \mu \mathrm{m}$ intervals were performed on selected areas at each of three maximum applied forces $(2,1$, and $0.4 \mathrm{mN})$.

In all cases, the force was also applied at a constant rate over a period of $20 \mathrm{~s}$. The maximum applied force was then held for $60 \mathrm{~s}$ to minimize the influence that creep has upon the measurement of contact stiffness. These precautions are necessary to ensure the measured transverse moduli are close to the true values. Furthermore, the maximum penetration depth during the indentation was controlled to be within $500 \mathrm{~nm}$, much smaller than the thickness of the composite layers $(5 \sim 10 \mu \mathrm{m})$. An Olympus LEXT OLS3100 confocal laser scanning microscope was used to identify the indent locations, layer thicknesses and surface morphology of the indented samples. Multiple surface roughness values were obtained across the nanoindentation area for each sample and average surface roughness values are presented here. It was, however, difficult to conduct nanoindentation on the crosssection of the layer, namely along the CNT axis, due to the relatively small layer thickness $(<10 \mu \mathrm{m})$ of the composites. Thus, the longitudinal elastic moduli of the composites have been deduced from the transverse moduli based on a volume averaged rule-of-mixtures.

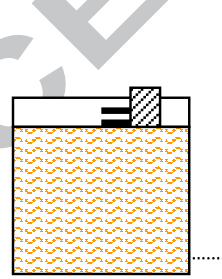

(a)

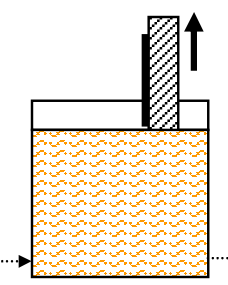

(b)

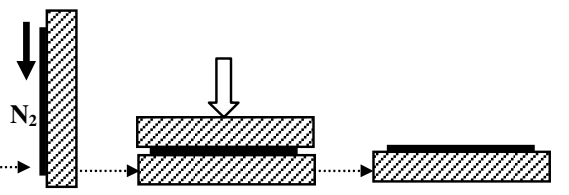

(d)

(e)
Figure 1. Schematic illustration of the realign and densification processes (not to scale). (a) in-situ wetting of vertically aligned CNT arrays in SU8 epoxy solution, (b) achievement of horizontally aligned CNTs by directionally pulling the substrate out of the solution, (c) blowing nitrogen gas along the arrow direction, (d) CNT compaction by applying arbitrary pressure on the top and (e) baking at $95{ }^{\circ} \mathrm{C}$ for 5 minutes followed by a hard bake at $200{ }^{\circ} \mathrm{C}$ for 20 minutes. 


\section{Results and discussion}

Figure 2 shows the as-grown CNT arrays composed of vertically aligned CNT forests.

Figure 2 (a) shows the samples before the pulling process (Figure 1b). The average diameter of the CNTs was estimated from high magnification SEM images (Figure 2C) which is approximately $20-30 \mathrm{~nm}$. This indicates multiwall CNTs (MWCNT). In previous work it was reported $[16,23]$ that the volume fraction of as-deposited thermal CVD CNTs is typically $1 \%$, which is reflected by the relatively large spacing $(>50 \mathrm{~nm})$ between CNTs as observed in Figure 2c. Figure 2c also shows that, although the overall CNT forests (Figure 2b) inherit the natural alignment generated from the growth process, at the micro/nano scale, individual CNT still exhibit a wavy structure which is characteristic of the CVD growth of nanotubes $[16,23]$. The length of the grown CNTs is in the range of $90-150 \mu \mathrm{m}$, varying across the substrates, generally shorter in the middle of the substrates and longer near the edges. The difference in growth rate is probably due to a slight variation of the temperature and flow of precursor gases across the tube furnace and the substrates. The thickness of the substrates could also play a role to the flow of the precursor gases.

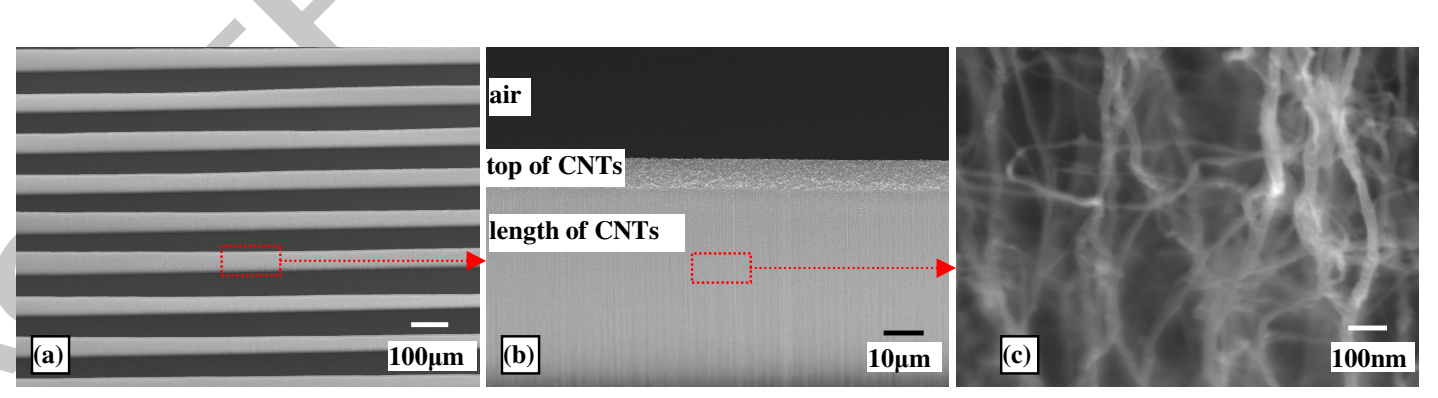

Figure 2. SEM images showing tilted views of a substrate with as-grown CNT arrays at three magnifications. This is prior to the re-align and densification processes. 
The processes shown in Figure 1 (a-e) led to flat composite "ribbons" consisting of horizontally aligned CNTs. The transformation of the CNTs from the vertical to horizontal direction when they were pulled out of the SU8 epoxy indicates that the capillary force has effectively overcome the elastic force associated with deforming the CNTs. Figure 3 (a) is a top optical view of sample B which shows the substrate after the pulling process (Figure 1b). The width of each individual ribbon corresponds to the length of the CNTs. It is noted that, since the CNT lengths in some areas are larger than the pre-defined spacing between arrays $(100 \mu \mathrm{m})$, overlapped ribbons are observed in these areas as shown in Figure 3(b). A detailed view in Figure 3(c) suggests that SU8 has effectively infiltrated in the voids between CNTs and provided lateral interconnections for the aligned CNTs in the composite. It is, however, unknown in this case whether SU8 has impregnated the hollow core of each CNT. The composite layer thicknesses for samples A, B, and C at the nanoindentation locations are approximately $2.2,9$ and $5 \mu \mathrm{m}$, respectively.
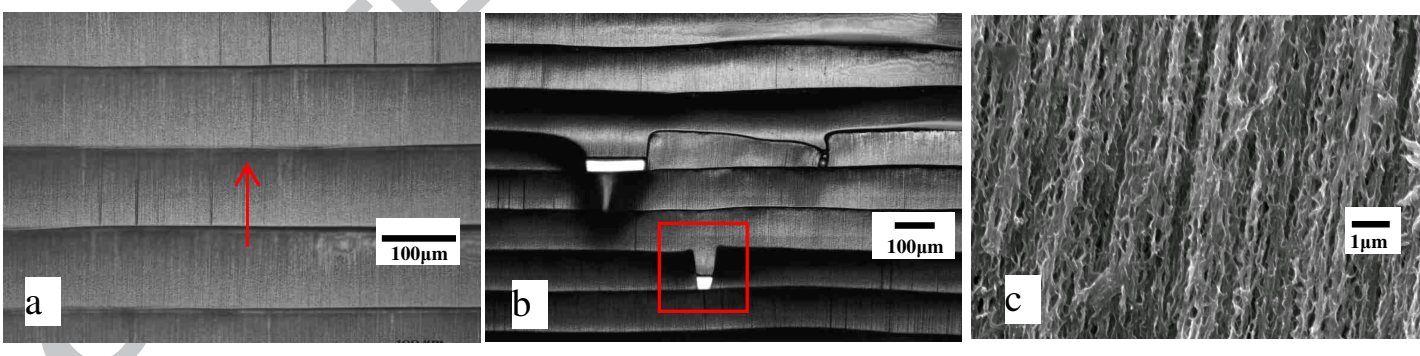

Figure 3. (a) Top optical view of sample B with horizontally aligned CNTs. (the arrow shows the "falling" direction of the CNT ribbons. (b) Overlapping CNT ribbons and a typical area is marked in a red box (c) SEM image of the composite (dark areas are SU8 and light areas are CNTs).

In order to assess the transverse modulus $(\mathrm{E} \perp)$ and volume fraction of $\mathrm{CNTs}\left(\mathrm{V}_{\mathrm{f}}\right)$ in the composites, a simple "Reuss model" [24] based on the equal stress treatment was used 
to provide a lower bound value for $\mathrm{E} \perp$ for a given $\mathrm{V}_{\mathrm{f}}$, i.e. a higher bound $\mathrm{V}_{\mathrm{f}}$ for a given $\mathrm{E} \perp$, as expressed in the following equation:

$$
E_{\perp}=\frac{E_{C N T} E_{S U 8}}{E_{S U 8} V_{f}+E_{C N T}\left(1-V_{f}\right)}
$$

where $E_{C N T}$ and $E_{S U 8}$ are the Young's modulus of CNT and SU8, respectively.

The Halpin-Tsai model [25] was used to give a higher bound value for E $\perp$, i.e. a lower bound on $\mathrm{V}_{\mathrm{f}}$ for a given $\mathrm{E} \perp$, as follows:

$$
E_{\perp}=\frac{E_{S U 8}\left(1+\xi \eta V_{f}\right)}{\left(1-\eta V_{f}\right)}
$$

in which

$\eta=\frac{\left(\frac{E_{C N T}}{E_{S U 8}}-1\right)}{\left(\frac{E_{C N T}}{E_{S U 8}}+\xi\right)}$

$\xi$ is a parameter which accounts for the fibre packing configuration. The value of $\xi$ is approximately unity as the reinforcement across the transverse cross section is similar [26]. $\xi=1$ was thus used in all subsequent calculations.

Figure 4 shows the comparison between the Reuss and Halpin-Tai estimates. The E $\perp$ values obtained from nanoindentation tests can then be used to estimate the upper and lower bounds of $\mathrm{V}_{\mathrm{f}}$ values using Equations (1) and (2), respectively. Since the simple rule-of-mixtures has a high degree of precision in predicting the longitudinal modulus 
$\left(E_{/ /}\right)[27,9]$, the obtained $V_{f}$ range can then be input in the following equation to deduce upper and lower values of $\mathrm{E}_{/ / \text {: }}$

$$
E_{/ /}=E_{S U 8}\left(1-V_{f}\right)+E_{C N T} V_{f}
$$

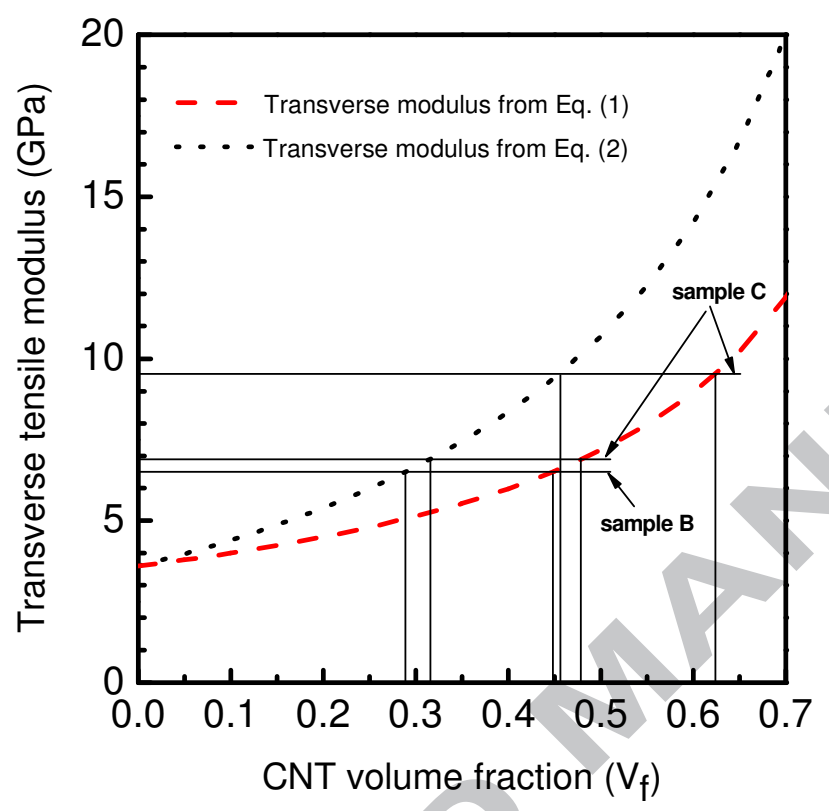

Figure 4. Comparison of upper and lower bound estimates of $\mathrm{V}_{\mathrm{f}}$ at given $\mathrm{E} \perp$ values as deduced from Equation (1) and (2), respectively. The straight lines are initiated to estimate $\mathrm{V}_{\mathrm{f}}$ values by using $\mathrm{E} \perp=6.4 \mathrm{GPa}$ for sample $\mathrm{B}$ and $\mathrm{E} \perp=6.4 \mathrm{GPa}$ and $9.6 \mathrm{GPa}$ for sample $\mathrm{C}$. These $\mathrm{E} \perp$ values are explained in the subsequent sections.

Figure 5 shows typical force-displacement (depth) nanoindentation curves of the tested samples. The force-increasing part of the indentation (i.e. curves connecting the origin and maximum depth point in Figure 5) is a combination of elastic and plastic deformation which results in the impression of the indenter shape on the surface, while only the elastic portion of the displacement is recovered during the unloading phase. The initial part of the force-removal curve is dominated by the elastic relaxation of the contact. Thus, the slope of the top part of the force-removal curve was used to determine the elastic modulus of the films according to ISO14577 parts 1 and 4 [21]. 
Figure 6 shows the measured modulus of the pure SU8 films plotted against the ratio of equivalent circular contact radius, a, to the composite layer thickness, $\mathrm{t}_{\mathrm{c}}$. A linear fit to

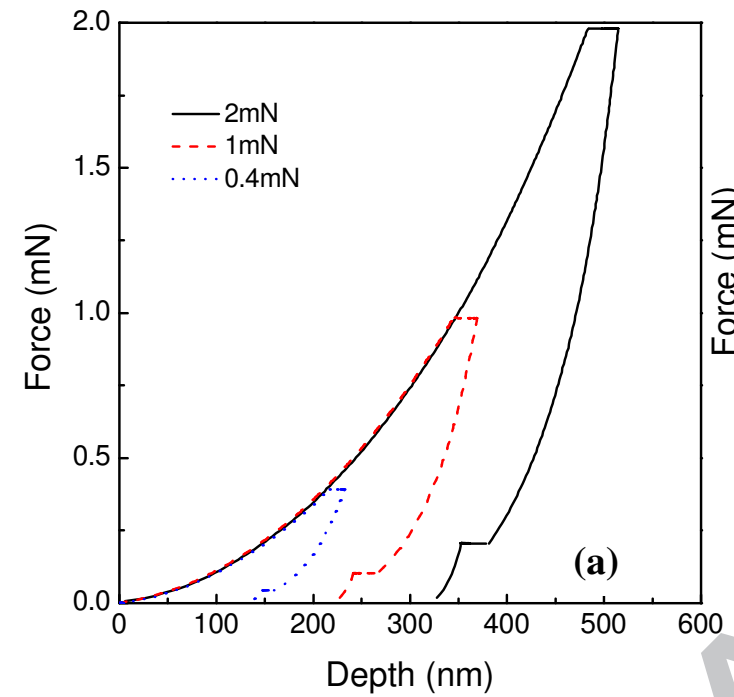

Figure 5. Representative nanoindentation force-displacement curves for (a) sample A measured using different maximum forces; (b) different samples A, B and C measured using $2 \mathrm{mN}$ maximum load.

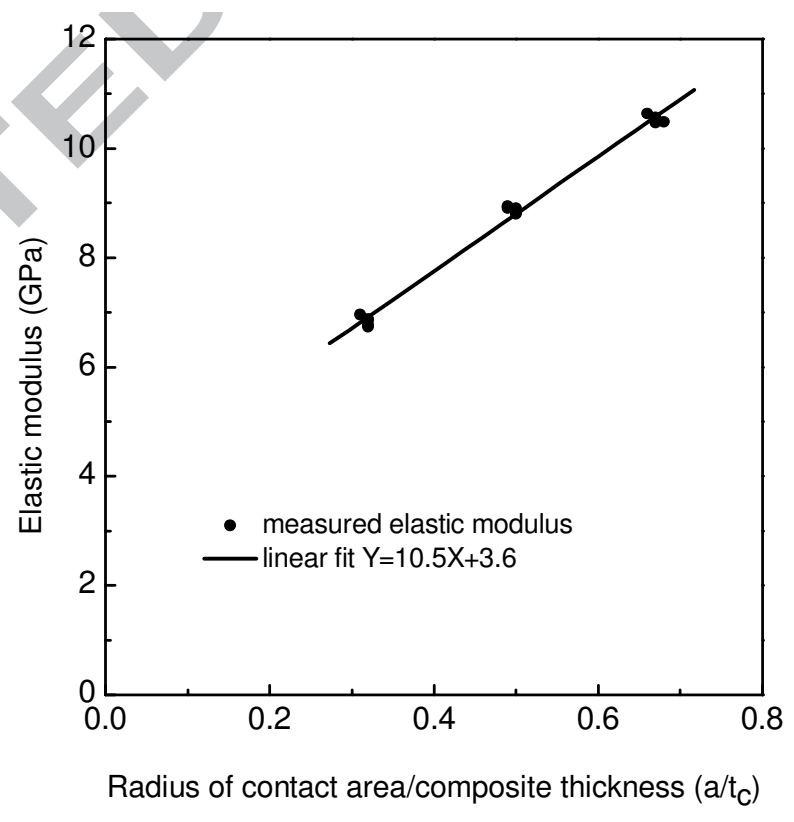

Figure 6. Measured modulus and a linear fit for sample A containing a pure SU8 epoxy film on the substrate. 
the data shows a positive slope, indicating the influence of the higher modulus (70-75 $\mathrm{GPa})$ of the $\mathrm{SiO}_{2}$ substrate layer immediate underneath the SU8 layer. The extrapolation of the linear fit to the modulus axis, at $\mathrm{a} / \mathrm{t}=0$, provides an estimate of the elastic modulus of neat SU8 epoxy as $3.6 \mathrm{GPa}$ at $95 \%$ confidence level, which is not significantly different from the reported value of $4.02 \mathrm{GPa}$ for hard baked SU8 (at $200^{\circ} \mathrm{C}$ for 30 minutes) [28]. Any slight softening is probably due to the slightly shorter hard bake time (20 minutes) in this work. 

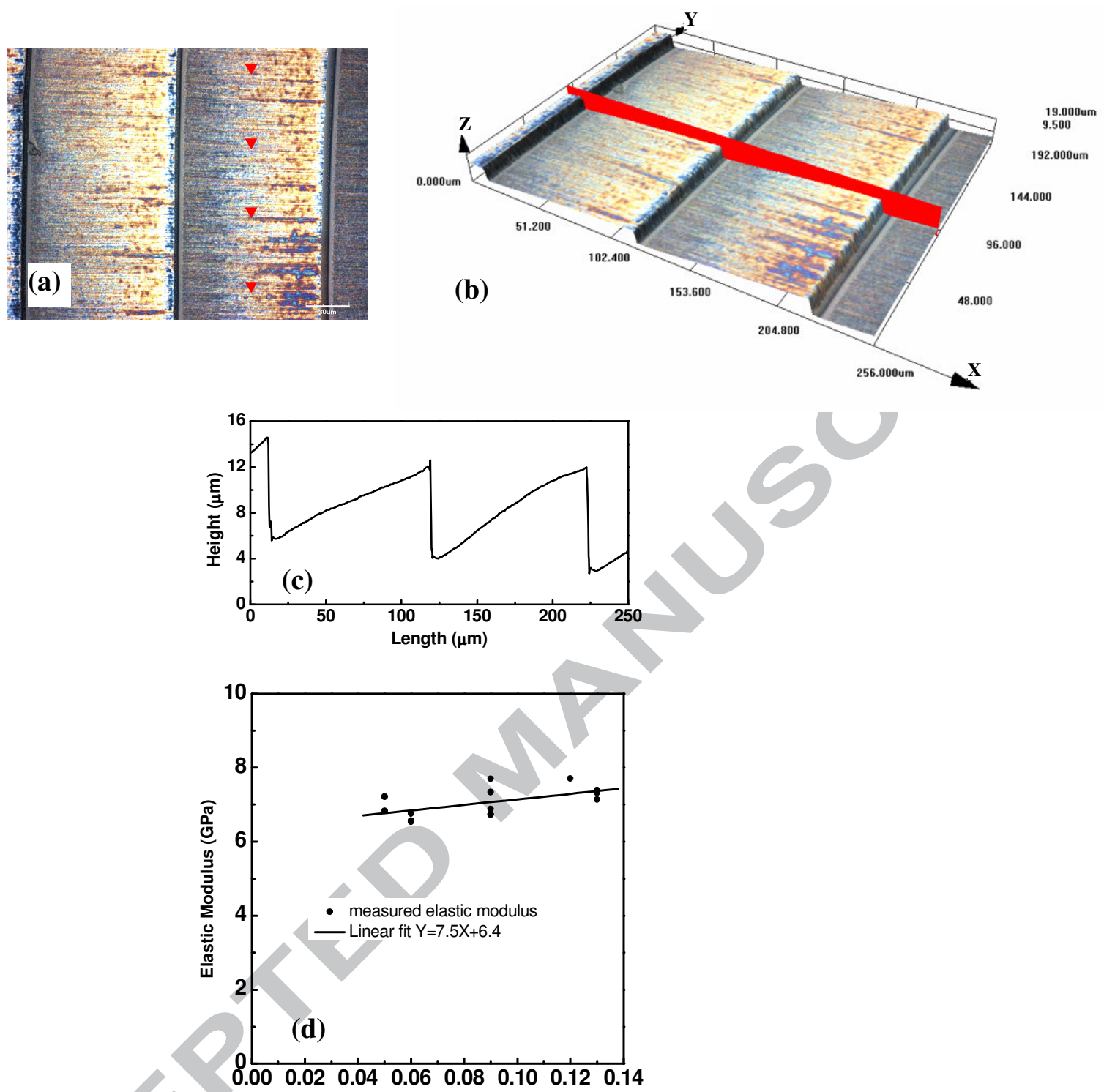

Radius of contact area/composite thickness $\left(a / t_{c}\right)$

Figure 7. (a) LEXT optical image of sample B with triangles indicating the indentation locations. (b) LEXT 3D optical image. (c) Profile of a crosssection as indicated in (b). (d) nanoindentation results and the linear fit.

Figure 7 shows the morphology profile and indent location for the majority of the areas on sample B. It was observed that, although each composite ribbon is flat, the simple pull-out process (Figure 1b) did not generate completely horizontal surfaces. As 
expected, all ribbon surfaces are tilted at an angle and present a slightly curved profile (Figure 7C). The average roughness of the indented ribbon surface is $98 \mathrm{~nm}$. Nonetheless, by extrapolating the linear fit in Figure 7(d), an elastic modulus of $6.4 \mathrm{GPa}$ was obtained which is almost twice that of neat SU8. By inputting $\mathrm{E}_{\mathrm{CNT}}=1 \mathrm{TPa}[29,30]$ and $\mathrm{E}_{\mathrm{SU} 8}=3.6 \mathrm{GPa}$ into Eq. (1) and (2), an upper and lower bound $\mathrm{V}_{\mathrm{f}}$ of $44 \%$ and $28 \%$ are obtained as indicated in Figure 4, suggesting that high volume fraction CNT reinforcement has been achieved. We acknowledge that the precise value of $\mathrm{E}_{\mathrm{CNT}}$ for the CNTs in the work may differ from the ideal value of $1 \mathrm{TPa}$. Nonetheless, since $\mathrm{E}_{\mathrm{CNT}}$ is much greater than $E_{\mathrm{SU}}$, some variation of $\mathrm{E}_{\mathrm{CNT}}$ value in $\mathrm{Eq.} \mathrm{(1)} \mathrm{and} \mathrm{(2)} \mathrm{will} \mathrm{not}$ significantly affect the results obtained. 
(a)

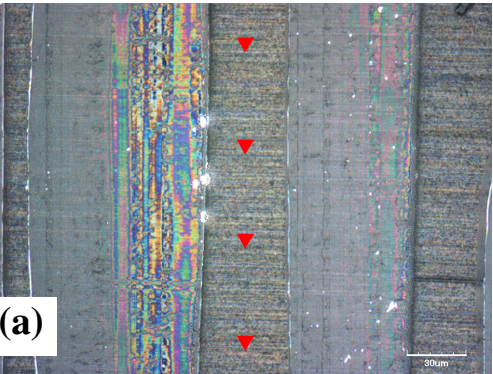

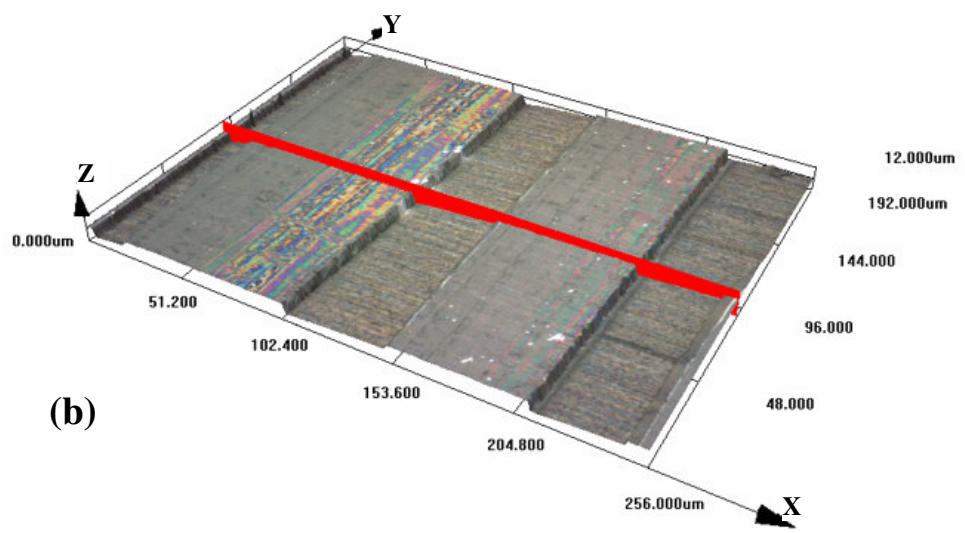
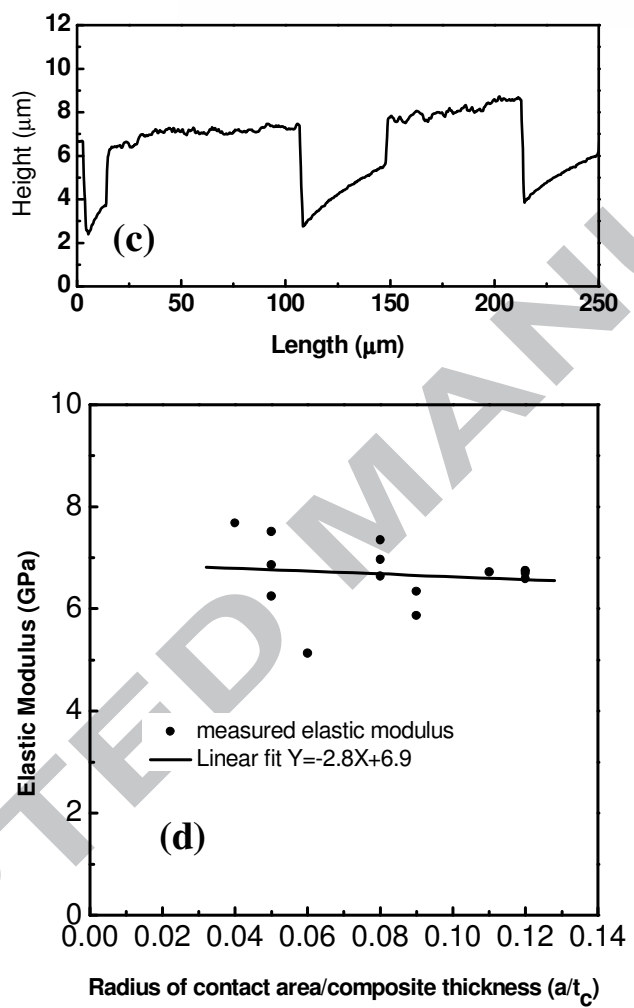

Figure 8. (a) LEXT optical image areas of samples $\mathrm{C}$ with overlapping CNT ribbons with triangles indicating the indentation locations. (b) LEXT 3D optical image. (c) Profile of a cross-section as indicated in (b). (d) nanoindentation results and the linear fit.

A non-uniform morphology across specimen $\mathrm{C}$ was observed, which contained patches with different ribbon heights. This was due to the length difference of the as-grown CNTs across the specimen. The non-uniform morphology can be avoided in future by designing an appropriate array spacing that matches the desired length of the CNTs. For 
areas in sample $\mathrm{C}$ with CNT lengths greater than $100 \mu \mathrm{m}$, overlapped ribbons were observed with a higher profile and the average roughness of the indented ribbon surface is $54 \mathrm{~nm}$. Although these higher patches have been effectively densified by the applied pressure, they also impeded the consolidation of the adjacent low profile regions. Figure 8 shows the $\mathrm{CNT} /$ composite ribbons with a mixture of overlapping and non-overlapping areas. It is observed that the applied pressure has indeed led to a more planar, horizontal surface in the region with elevated profile. In these areas, compression has taken place to bring the CNTs into closer arrangement (i.e. higher density). This is also indicated by the greater ribbon height in Figure $7 \mathrm{C}(\sim 14 \mu \mathrm{m})$ than that in Figure $8 \mathrm{C}(\sim 8 \mu \mathrm{m})$. Since the non-overlapping areas have not been compressed effectively, in these areas, nanoindentation results in Figure 8(d) suggest an elastic modulus of $6.9 \mathrm{GPa}$, similar to that of sample $\mathrm{B}$. This corresponds to an upper bound $\mathrm{V}_{\mathrm{f}}=48 \%$ and a lower bound $\mathrm{V}_{\mathrm{f}}=32 \%$ indicated in Figure 4.

Nanoindentation tests have also been carried out on sample $\mathrm{C}$ areas where only single layers of CNT/composite ribbons are present. Figure 9 shows that, in these areas, all the CNT/composite ribbons have been uniformly densified by the applied pressure and the average roughness of the indented ribbon surface is $90 \mathrm{~nm}$. Figure 9 (d) indicates a transverse modulus of approximately $9.6 \mathrm{GPa}$, over 2.5 times greater than that of neat SU8. This transverse modulus suggests that $\mathrm{V}_{\mathrm{f}}$ between $46 \%$ and $63 \%$ has been achieved (Figure. 4). We acknowledge that the estimation of upper and lower $V_{f}$ values from $\mathrm{E} \perp$ is prone to some error. However, it has been proven [31] that transverse moduli of long fibre composites, which is the case for this work, agree well with the HalpinTsai model. Direct observation of $\mathrm{V}_{\mathrm{f}} \mathrm{using}$ microscopic means has proven to be difficult 
and is also prone to some error as it is challenging to gain clear observation of individual CNTs across a relatively large cross-section area. Nonetheless, SEM was used to observe the vertical ribbon edge of a CNT/SU8 composite layer after consolidation in sample $\mathrm{C}$ with a view to gaining cross-section information as shown in Figure 10. We assume that the "white dots" in Figure 10b represent ends of individual CNTs. By using ImageJ for image processing, the CNT content was highlighted in Figure 10c. An adaptive threshold algorithm [32] was employed to roughly assess $V_{f}$. This led to the approximate estimation of $\mathrm{V}_{\mathrm{f}} \sim 50 \%$ which seems to be in line with the above-predicated range of $46 \% \sim 63 \%$. To the best of our knowledge, this is the highest $\mathrm{V}_{\mathrm{f}}$ reported for composites with horizontally aligned CNTs. 

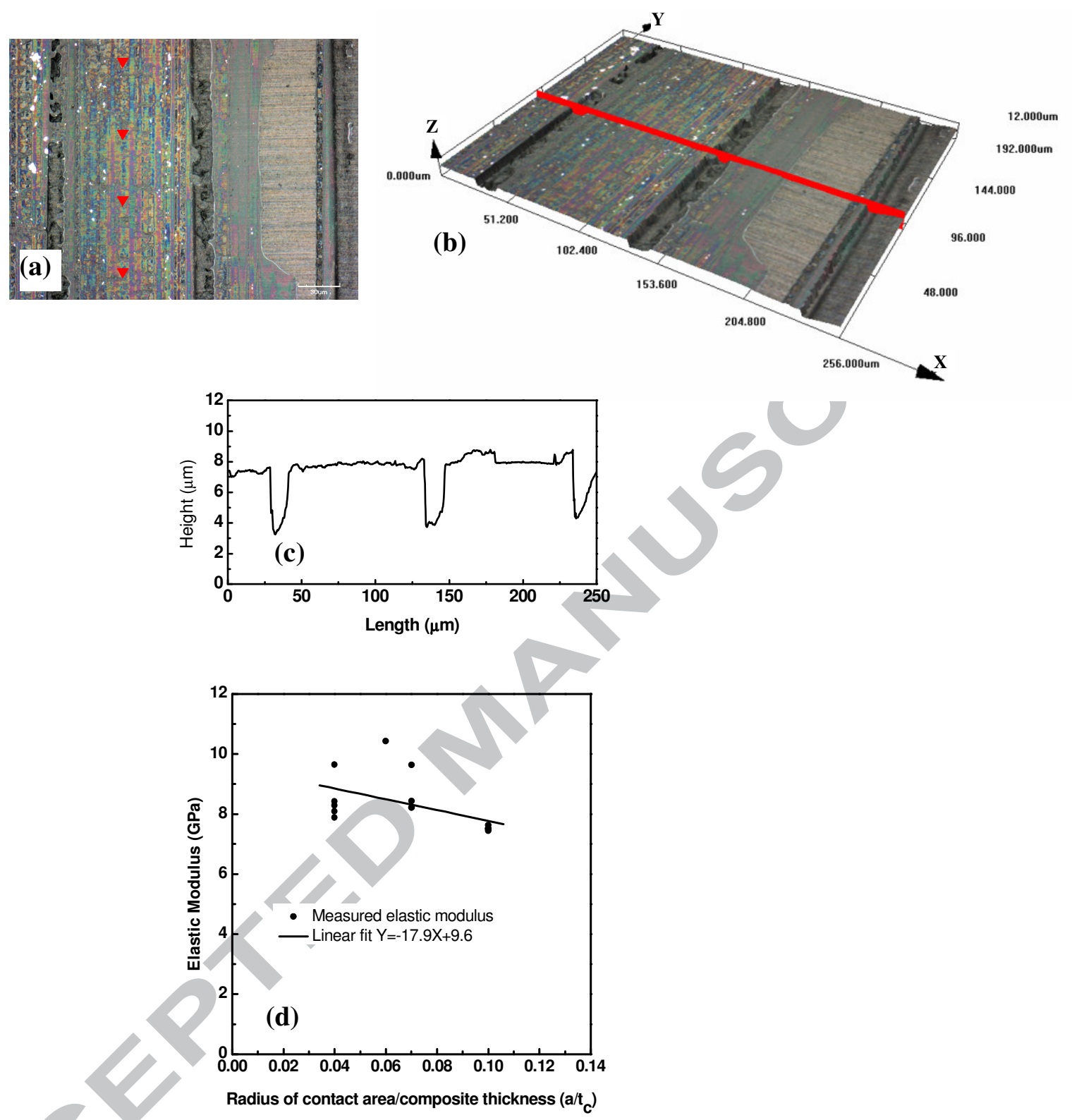

Figure 9. (a) LEXT Optical image areas of samples $\mathrm{C}$ with single layer SU8/CNT ribbons with triangles indicating the indentation locations. (b) LEXT 3D optical image. (c) Profile of a cross-section as indicated in (b). (d) nanoindentation results and the linear fit.

Despite the possible error associated with $V_{f}$ estimation, the correlation between the increasing $\mathrm{V}_{\mathrm{f}}$ values and the consolidation process was clearly observed. This indicates an effective densification process demonstrated by sample B and C. In particular, for 

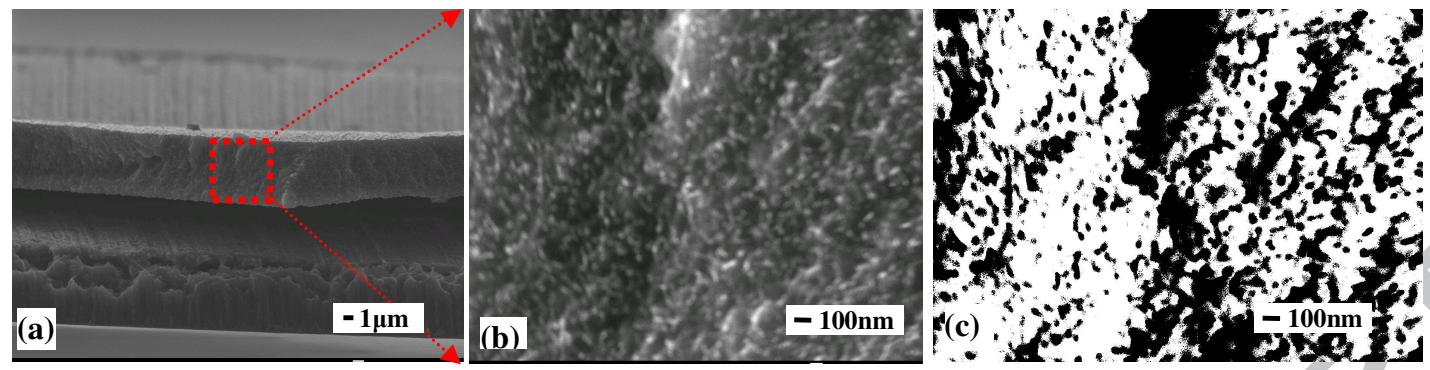

Figure 10. (a) Cross-section of composite layers in sample $C$ as observed from x-axis direction shown in Figure 8b; (b) enlarged image of the selected area marked in the red box in (a); (c) processed image to highlight CNTs in (b) which was used for approximate estimation of $\mathrm{V}_{\mathrm{f}}$.

sample B, the capillary force has not only transformed the CNT arrays from vertical to horizontal alignment, but also effectively brought the CNTs into a closer arrangement probably assisted by the surface tension [33]. Thus, $V_{\mathrm{f}}$ is increased as in Figure 3(c) in comparison with that in Figure 2(c), which led to improved mechanical properties. The subsequent pressurized consolidation process has been proven to be effective for sample $\mathrm{C}$, leading to a further improvement of $\mathrm{V}_{\mathrm{f}}$ to $46 \% \sim 63 \%$ (Fig. 10) and thus the increased transverse modulus. This differs from a previously reported "dry" densification process [16], in which the CNT forests were compressed prior to the polymer wetting process. The consolidation step in the present work was carried out immediately after the in-situ CNT/SU8 wetting. This allows both capillary forces and applied pressures to contribute to $\mathrm{V}_{\mathrm{f}}$ improvement. We believe that $\mathrm{V}_{\mathrm{f}}$ could also be tailored by careful control of the applied pressure. Furthermore, we acknowledge that the direct measurement of the original CNT alignment and the extent to which this may be improved by the realign and consolidation process is as yet not possible. However, we believe the vertical alignment of the as-grown CNTs was likely transferred to horizontal alignment through the developed process. The alignment is anticipated to be significantly higher than those achieved by conventional means in which randomly arranged CNTs are combined with polymer matrices to form composites. 
Longitudinal moduli of the composites have been deduced from Eq (3). By inputting the $\mathrm{V}_{\mathrm{f}}$ values of sample B (28\% 44\%) and C (46 63\%) into Equation (3), longitudinal moduli of approximately 280 440 GPa and 460 630 GPa were obtained for sample B and C, respectively, as shown in Figure 11. These are over two orders of magnitudes higher than that of neat SU8 and also easily exceed that of silicon (130-185 GPa). Furthermore, the developed densification process is compatible and can be practically scaled up for practical microfabrication processes. Thus, these developed composites are highly attractive for the exploitation as advanced structural materials for MEMS such as high performance microactuators. For example, for bending mode resonators with simple beam structures (e.g. suspended microcantilevers), the developed composites can be used to form the beam structures, in which the reinforcement CNTs are well aligned with the beam axis. The high specific modulus induced by the horizontal alignment can then lead to a high resonant frequency $[9,34]$. The experimental verification of the longitudinal moduli and the achievement of such high performance microresonator and microactuator prototypes using these composites will be the main focus of future work.

\section{Conclusions}

A practical process has been developed to achieve SU8 epoxy composite films reinforced with horizontally aligned and high volume fraction CNTs. SU8 composites with CNT volume fractions of up to $63 \%$ have been successfully demonstrated which has led to a more than twofold increase of the transverse elastic modulus (9.6 GPa), compared to that of pure SU8 (3.6 GPa). Based on these values, the longitudinal moduli of up to $630 \mathrm{GPa}$ is inferred, which is over two orders of magnitude higher than that of 
pure SU8, and significantly higher than that of silicon. The high longitudinal modulus is crucial for potential applications in high speed MEMS resonators and actuators.

Implementation and characterisation of such microactuators (e.g. microbeams) using the developed composites will be the focus of future work. We predict that the developed techniques can also be potentially exploited for various composites composed of different types of polymer matrices so that multifunctional materials with low density, high strength and high electrical conductivities could also be obtained, providing advanced materials for a wide range of applications.

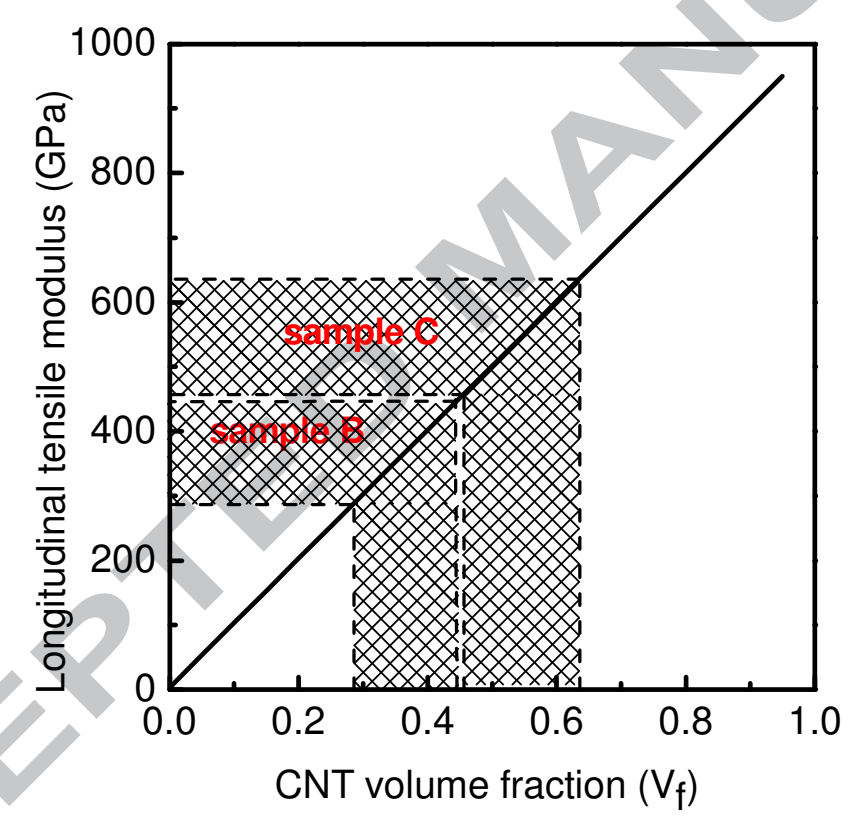

Figure 11. Estimation of longitudinal modulus for sample B and C, respectively, as a function of CNT volume fraction. 


\section{References:}

[1] Iijima S, Helical microtubules of graphitic carbon. Nature 1991; 354(6348):56.

[2] Dalton AB, Collins S, Munoz E, Razal JM, Ebron VH and Ferraris JP, Super-tough carbon-nanotube fibres - These extraordinary composite fibres can be woven into electronic textiles. Nature 2003; 423 (6941): 703.

[3] Ruan SL, Gao P,Yang XG and Yu TX, Toughening high performance ultrahigh molecular weight polyethylene using multiwalled carbon nanotubes. Polymer 2003; 44(19): 5643-5654.

[4] Seo MK and Park SJ, Electrical resistivity and rheological behaviors of carbon nanotubes-filled polypropylene composites. Chemical Physics Letters 2004; 395 (1-3): $44-48$.

[5] Ramamurthy PC, Malshe AM, Harrell WR, Gregory RV, McGuire K and Rao AM, Polyaniline / single-walled carbon nanotube composite electronic device. Solid-State Electronics 2004; 48 : 2019-2024.

[6] Odegard GM, Gates TS, Wise KE, Park C and Siochi EJ, Constitutive modelling of nanotube-reinforced polymer composites. Composites Science and Technology 2003; 63 (11):1671-1687.

[7] Paiva MC, Zhou B, Fernando KAS, Lin Y, Kennedy JM and Sun Y, Mechanical and morphological characterization of polymer-carbon nanocomposites from functionalized carbon nanotubes. Carbon 2004; 42(14): 2849-2854.

[8] Spitalsky Z, Tsoukleri G, Tasis D, Krontiras C, Georga SN and Galiotis C, High volume fraction carbon nanotube-epoxy composites. Nanotechnology 2009; 20(40) 405702 (7pp). 
[9] Ashrafi B, Hubert P and Vengallatore S, Carbon nanotube-reinforced composites as structural materials for microactuators in microelectromechanical systems. Nanotechnology 2006; 17 (19): 4895-4903.

[10] Fang W, Chu H, Hsu W, Cheung T and Tai N, Polymer-Reinforced, Aligned Multiwalled Carbon Nanotube Composites for Microelectromechanical Systems Applications. Advanced Materials 2005; 17 (24): 2987-2992.

[11] Jang MW, Lu M, Cui T and Campbell S A, Functional 1.6 GHZ MEMS switch using aligned composite CNT membrane by dielectrophoretic self-assembly. Proc. TRANSDUCERS'2009;912-915.

[12] Li Y L, Kinloch IA and Windle A H, Direct spinning of carbon nanotube fibers from chemical vapor deposition synthesis. Science 2004; 304 (5668): 276-278.

[13] Zhang M, Atkinson K R and Baughman R H, Multifunctional Carbon Nanotube Yarns by Downsizing an Ancient Technology. Science 2004; 306(5700): 1358-1361.

[14] Miaudet P, Badaire S, Maugey M, Derre A, Pichot V and Launois P, Hot-Drawing of Single and Multiwall Carbon Nanotube Fibers for High Toughness and Alignment. Nano Lett.2005; 5(11): 2212-2215.

[15] Liu L Q, Tasis D, Prato M and Wagner HD, Tensile Mechanics of Electrospun Multiwalled Nanotube/Poly(methyl methacrylate) Nanofibers. Adv. Mater.2007; 19 (9):1228-1233.

[16] Wardle BL, Saito DS, Garcia EJ, Hart AJ, de Villoria RG and Verploegen EA, Fabrication and Characterization of Ultrahigh-Volume- Fraction Aligned Carbon Nanotube-Polymer Composites. Adv. Mater.2008; 20(14): 2707-2714.

[17] Madou MJ, Fundamentals of microfabrication — the science of miniaturization, 2nd ed. CRC Press; 2002. 
[18] Srikar V T and Spearing SM, Materials selection for microfabricated electrostatic actuators. Sensors and Actuators, Part A, Physical 2003; 102(3): 279-285.

[19] Srikar V T and Spearing S M, Materials selection in micromechanical design: an application of the Ashby approach. J. MicroElectromechanical Systems 2003; 12 (1): 310.

[20] Srinivasan P and Spearing SM, Materials Selection and Design of Microelectrothermal Bimaterial Actuators. J. Microelectromechanical Systems 2007; 16(2): 248-259.

[21] Jennett NM, Reliable measurement of coatings' properties by instrumented indentation according to ISO14577- 4. VDI Berichte 2006;1948 : 61-71. Publ. VDIVerlag GmbH Dusseldorf.

[22] Jennett NM, Aldrich-Smith G and Maxwell AS, Validated measurement of Young's modulus, Poisson ratio and thickness for thin coatings by combining instrumented nanoindentation and acoustical measurements. J. Mater. Res.2004; 19(1): $143-148$.

[23] Tawfick S, O'Brien K and Hart AJ, Flexible high-conductivity carbon-nanotube interconnects made by rolling and printing. Samll(2009); 5(21): 2467-273.

[24] Chou T W, Microstructural Design of Fiber Composites, 1992,(Cambridge:

Cambridge University Press)

[25] Halpin JC and Tsai SW, Air Force Technical Report AFML-TR 67-423. 1967, Dayton, OH: Wright Aeronautical Laboratories.

[26] Halpin JC and Kardos JL, Halpin-Tsai equations: A review. Polymer Engineering and Science 1976; $16(5): 344-352$. 
[27] Hull D and Clyne T W, An introduction to composite materials. Cambridge University Press, 1996, UK.

[28] Lorenz H, Despont M, Fahmi N, LaBianca N, Renaud P and Vettinger P, SU-8: a low-cost negative resist for MEMS. J. Micromechanics Microeng.1997; 7(3): 121-124. [29] Yu MF, Lourie O, Dyer MJ, Moloni K, Kelly TF and Ruoff RS, Strength and breaking mechanism of multiwalled carbon nanotubes under tensile load. Science 2000 ; $287(5453)$ : 637-640.

[30] Khang DY et al. Molecular scale buckling mechanics in individual aligned singlewall carbon nanotubes on elastomeric substrates. Nano Lett. 2008; 8 (1) 124-130.

[31] Wolfenden A and Wolla JM, Mechanical damping and dynamic modulus measurements in alumina and tungsten fibre reinforced aluminium. J. Mater. Sci.1989; 24(9): 3205-3212.

[32] Ridler TW, Picture thresholding using an iterative selection method. IEEE Trans Syst Man Cybern 1978;8:630-632.

[33] Shimoda H, Oh SJ, Geng HZ, Walker RJ, Zhang XB, McNeil LE and Zhou O, Self-Assembly of Carbon Nanotubes. Adv. Materials 2002; 14 (12): 899-901. [34] Ashby MF, Materials Selection in Mechanical Design.Oxford: ButterworthHeinemann; 2001. 